\title{
Control Technology on Surface Runoff Pollution: A Review
}

\section{Chaocheng Zheng*}

\author{
Nanjing Vocational Institute of Transport Technology, Nanjing 211188, China. \\ *zccnau@126.com
}

Keywords: Surface runoff; pollution; control technology.

\begin{abstract}
There are a lot of pollutants in the road runoff. If they are not controlled, it will seriously affect the water quality of natural water. Therefore, it is of great significance for the development of the city to develop a technology to control road runoff and reduce the pollution of the surface source. Hence, urban drainage system and non-point source pollution, as well as its control technology of surface runoff and surface source pollution were reviewed on this paper.
\end{abstract}

\section{Urban Drainage System and Non-Point Source Pollution}

Now most countries rely mainly on city rainwater pipe network system discharges, storm sewer system rain water will be discharged to the nearest sewage treatment plant or natural river, the traditional way of discharge that formed in nineteenth Century cannot meet the growing demands of modern city drainage. Due to the increase of the area of impervious and underlying surface and the reduction of the space of rainwater and the frequency of extreme weather, the existing inefficient urban drainage system has been unable to meet the development of the city, making more and more cities beset by urban water logging. According to statistics, during the 2008-2010-year period, 213 cities and cities at the county level in our country suffered from urban water logging. At the same time, there are a lot of pollutants in the road runoff. If they are not controlled, it will seriously affect the water quality of natural water. Therefore, it is of great significance for the development of the city to develop a technology to control road runoff and reduce the pollution of the surface source. Hence, the development of urban drainage system and the process of urbanization are inseparable, and urbanization has a great impact on the drainage system. Urbanization is the development trend of the whole world, especially in China, the speed of urbanization arouses more attention to the world. According to China's statistical yearbook, China's urbanization rate increased from $13.2 \%$ to $50 \%$ from 1953 to 2011 , which is likely to reach $60 \%$ by 2020 . With the rapid development of urbanization and social economy, urbanization has also greatly changed our natural environment, which has brought great challenges to urban public facilities, especially the new requirements for urban drainage system. First of all, concrete and asphalt pavement are widely used in urban construction, and the water surface of the city is greatly reduced. A large increase in the water surface has destroyed the original ecological water circulation system, and the rainwater lacks effective infiltration channels, resulting in a great increase in rainwater runoff.

Nowadays, most cities in the world take the urban pipe network system as the main way of drainage, but with the deepening of urbanization, the urban pipe network has been increasingly unable to meet the needs of urban development. Our city is in the drainage system as the main drainage way, by the end of 2020, China's city drainage network will reach 865 thousand kilometers in length. The drainage system in China is mainly divided into confluence system and distribute system. The confluence system can be divided into 3 types: the straight row confluence system, the intercepted confluence system and the fully processed confluence system. The diversion system can be divided into complete diversion system, entrapment diversion system and incomplete shunt system.

The drainage system in China is mainly divided into confluence system and distributor system. The confluence system can be divided into 3 types: the straight row confluence system, the intercepted confluence system and the fully processed confluence system. The diversion system can 
be divided into complete diversion system, entrapment diversion system and incomplete shunt system.

Relative to the drainage system of foreign countries, China's existing drainage system there are more problems, mainly reflected in the design of the low return period, the development of drainage planning lags far behind the city, the lack of long-term planning of drainage system in the city's development process, the development of the drainage system to keep up with the development of the city, often cannot meet the water requirements.

Table 1. Demand for Reappearance Period of Urban Drainage Design.

\begin{tabular}{cccc}
\hline & Central city & Non-central urban area & Important area of central city \\
\hline Mega city & $3-5$ & $2-3$ & $5-10$ \\
Big city & $2-5$ & $2-3$ & $5-10$ \\
Medium and small cities & $2-3$ & $2-3$ & $3-5$ \\
\hline
\end{tabular}

Although the design of life in design standard setting has been very low, but in the process of construction, due to the restriction of construction cost, often take the minimum design life, the drainage capacity of pipeline system is relatively low, in the presence of high intensity rainfall, cannot achieve the purpose of rapid discharge, the City water logging occurs.

Urban non-point source pollution has become an important factor in the pollution environment and has attracted more and more attention at home and abroad. The non-point source pollution is characterized by the dispersion of the pollution sources, the more varied ways of pollution, the many kinds of pollutants and the more difficult to control the source of the pollution. For example, Bertrand-Krajewski is defined for the start of the 30\% first flush rainfall contains more than $80 \%$ pollutants, this definition has not been all that, but scholars believe that the pollutants in the first flush of more than the total amount of pollutants in runoff. In this case, Kayhanian and Stenstrom proposed the concept of the initial scour index.

$$
\mathrm{MFF}_{\mathrm{r}}=\frac{\mathrm{R}_{\mathrm{V}}}{\mathrm{M}_{\mathrm{s}}}
$$

Among them: MFFr: initial scour index

Rv: define the proportion of rainfall when the initial scour accounts for the proportion of the total rainfall

Ms: the amount of pollutants contained in the rainfall RV accounts for the proportion of the total pollutants

For example, $10 \%$ of the rainfall in the initial definition contains $30 \%$ pollutants, MFF10 is the proportion of $30 \%$ in addition to the initial pollutant rainfall proportion is $10 \%$, MFF 10 is 3 , when only MFFr is greater than 1 of the time to define the first flush phenomenon, when there is no MFFr $<1$ first flush phenomenon. The initial scour index can be used to describe the initial scour phenomenon more flexibly by the initial scour index.

Through the study, it is found that the initial scour is related to many factors, and the initial scour has different effects on different pollutants. It was found in the study that the first $20 \%$ of the rainfall contains COD: $32 \%$, TOC: $34 \%$, SS:36\%, T-N:42\%, T-P:50\%. In different areas, the law of initial scour is different. In Kim, it is found that pollutants in different functional areas are affected differently by initial scour. $\mathrm{TP}>\mathrm{SS}>\mathrm{COD}>\mathrm{TN}$, in the urban neighborhood, is $\mathrm{SS}>\mathrm{COD}>\mathrm{TP}>\mathrm{TN}$. At the same time, there is a great relationship between the initial scour and rainfall intensity. Li Chunlin and other studies found that at the beginning of rainfall, the initial scour phenomenon is positively correlated with rainfall intensity and rainfall.

\section{Control Technology of Surface Runoff and Surface Source Pollution}

\subsection{Research Status of Surface Runoff and Non-Point Source Pollution Control of Domestic and External}

Since 70s twentieth Century, drainage mode based on low impact development concept is showing advantages gradually compared to the drainage way of pipeline network as drainage terminal. Low impact development concept (Low Impact Development, LID) is in the process of city construction to 
minimize the impervious surface area, the rainwater runoff in the source collection, infiltration treatment, to control the runoff; in the control of water at the same time, but also can reduce the impact of non-point source pollutants in the runoff of natural water.

Some domestic scholars have begun to pay attention to the related technology research on control of runoff, especially the related technologies based on the LID concept. Now the domestic research on the single LID technology has made some progress, some research results will also be applied to practical engineering, such as the Beijing Olympic Park and Shanghai World Expo Pavilion construction in the application of the LID technology, to better control effect on the runoff. But there are still few plans for a large scale. The Ministry of housing and construction has issued a document in 2016 to make all the cities complete the relevant regulations on rainwater control. At the same time, there are still few related regulations on the control of rainwater runoff in China. Therefore, there are still some problems in the application of LID technology in China, which needs further research.

\subsection{Low Impact Development Technology}

Table 2. Description and Function of Main LID Technology.

\begin{tabular}{|c|c|c|c|c|c|c|}
\hline \multirow[b]{2}{*}{$\begin{array}{c}\text { Low impact development } \\
\text { technology }\end{array}$} & \multirow[b]{2}{*}{ Description } & \multicolumn{5}{|c|}{ Column Header Goes Here } \\
\hline & & $\begin{array}{l}\text { Buffer flow } \\
\text { velocity }\end{array}$ & Infiltration & $\begin{array}{c}\text { Water } \\
\text { holding } \\
\text { capacity }\end{array}$ & retention & $\begin{array}{l}\text { Water } \\
\text { quality } \\
\text { control }\end{array}$ \\
\hline Bio detained pool & $\begin{array}{l}\text { plant covered facility to } \\
\text { collect runoff }\end{array}$ & & $\sqrt{ }$ & $\sqrt{ }$ & $\sqrt{ }$ & $\sqrt{ }$ \\
\hline $\begin{array}{l}\text { Rapid infiltration system } \\
\text { for rainwater }\end{array}$ & $\begin{array}{l}\text { permeable medium } \\
\text { filled with gravel to } \\
\text { collect rain water }\end{array}$ & & $\sqrt{ }$ & & & $\sqrt{ }$ \\
\hline Rainwater garden & $\begin{array}{l}\text { Artificial excavation to } \\
\text { deal with the rain }\end{array}$ & & $\sqrt{ }$ & & $\sqrt{ }$ & $\sqrt{ }$ \\
\hline Artificial wetland & $\begin{array}{l}\text { materials to treat } \\
\text { collected rainwater }\end{array}$ & & $\sqrt{ }$ & & $\sqrt{ }$ & $\sqrt{ }$ \\
\hline Asakusa ditch & $\begin{array}{l}\text { covered with turf to } \\
\text { control water quality. }\end{array}$ & $\sqrt{ }$ & & & & $\sqrt{ }$ \\
\hline Permeable pavement & $\begin{array}{l}\text { infiltration to control } \\
\text { water quality }\end{array}$ & & $\sqrt{ }$ & & & $\sqrt{ }$ \\
\hline Rainwater collector & collection containers & & & $\sqrt{ }$ & & \\
\hline Green roof & $\begin{array}{l}\text { High permeability } \\
\text { materials covered on } \\
\text { building }\end{array}$ & $\sqrt{ }$ & & & $\sqrt{ }$ & $\sqrt{ }$ \\
\hline
\end{tabular}

Low impact development (LID) technology mainly includes permeable pavement, constructed wetland, rain garden, green roof, etc. each technology has different functions and functions. The research group has made a certain research on the technology of rainwater rapid infiltration system, rainwater garden and artificial wetland, and the main characteristic of each technology is listed in Table.

\section{Permeable Pavement}

\subsection{Introduction of Permeable Pavement}

The surface layer of permeable pavement contains a large number of pores, when rainfall occurs, the first will be carried out on the surface of the pore infiltration, so as to effectively control the surface runoff, reduce dependence on city network; at the same time the rain in permeable pavement infiltration, a large number of non-point source pollution is interception, avoid pollution the pollution of natural water source. The top down of the permeable pavement is mainly composed of the surface layer, the leveling layer, the base layer and the cushion layer.

\subsection{Classification of Permeable Pavement}

According to the surface layer of permeable pavement can be divided into pervious concrete pavement, porous asphalt pavement, permeable brick, grass planting brick chain and plastic brick. Pervious concrete is made of coarse aggregate with fine gravel instead of fine sand as aggregate. It is made of concrete, coarse aggregate and additives. It is formed by combining concrete with additives 
and filling with no fine particles between aggregates. Pervious concrete contains the porosity of $10 \%-35 \%$, allowing the rain to permeate through the pores. Because porous concrete contains more pores, the compressive strength of permeable concrete pavement is mainly dependent on the degree of cementation between aggregates. The greater the pore size of aggregate, the easier it is to bear bone when subjected to pressure. The dislocation between the materials is deformed, and the permeable pavement is destroyed. In general, the porosity and compression ability of the permeable pavement are inversely proportional, which are mainly used in the pavement or on the light load pavement. Permeable asphalt pavement is made of asphalt particles cemented together with different sizes, but compared with traditional asphalt pavement, there are fewer particles. It is similar to the permeable concrete pavement with the porosity of $15 \%-35 \%$. The surface of the permeable asphalt pavement looks similar to the traditional asphalt pavement, but its compression ability is lower than that of the traditional permeable pavement. It is mainly used in low - flow, low - speed, low - load roads.

\subsection{Pervious Pavement Design}

In the design of water permeable road surface, first of all, we must determine the reappearance period of the design rainfall of the permeable pavement, that is, the maximum rainfall intensity can be resisted by the surface of the permeable road. The rainfall intensity can be determined by the next type.

In the form:

$$
q=\frac{167 A(1+\operatorname{cog} P)}{(t+b)^{n}}
$$

$\mathrm{P}$ - Design reappearance period, a;

$\mathrm{T}$ - rainfall duration, min;

A - force varies with heavy rain, the current $P$;

$\mathrm{N}$ - rainstorm attenuation index;

$\mathrm{B}$ - time parameters;

C - rainfall parameters.

When rainwater mainly depends on soil foundation infiltration, the thickness of the permeable pavement can be determined by the lower type.

$$
\begin{gathered}
\mathrm{H}_{\mathrm{d}}=\left(0.1 \mathrm{i}-3600 \mathrm{~K}_{\mathrm{c}}\right) \frac{100 \mathrm{t}}{60 V} \\
\mathrm{~V}=\frac{H 1 V 1+H 2 V 2+H 3 V 3}{H 1+H 2+H 3}
\end{gathered}
$$

In the form:

$\mathrm{Hd}$ : the predesign thickness of the permeable pavement, $\mathrm{cm}$;

Kc: the permeability coefficient of the soil base of the pervious pavement, $\mathrm{cm} / \mathrm{s}$;

$\mathrm{V}$ : the average porosity of the pavement is designed, \%;

$\mathrm{H}$ : thickness of the surface layer, the base and the cushion of the water permeable road, $\mathrm{cm}$;

\subsection{Research Status of Permeable Pavement}

The foreign scholars have studied the infiltration characteristics of rainwater in the permeable pavement. Scholz permeable surface layer is divided into two categories, a surface layer material is continuous, the surface layer itself through pore infiltration, the surface layer material mainly includes pervious concrete; another surface material is separate and not continuous, the surface layer through the gap the material between the infiltration, including water permeable brick etc. William and others divide the process of rainwater infiltration into four stages: infiltration, accumulation, runoff and drying, and the hydraulic characteristics of each process are studied respectively.

The permeable road mask has a larger permeability coefficient, which can reduce the runoff of the pavement. Luis A monitoring found that under the 100-year rainfall intensity, the surface runoff of different types of water permeable roads would not be produced. Compared with the effect of surface layer materials, Kelly A et al. Found that the basic characteristics have greater impact on the permeable pavement. Different from the traditional road base, the base of the permeable road has a large number of pores, and the characteristics of the pore are the important factors that affect the 
permeability coefficient of the permeable pavement. Sans alone studied the relationship between porosity and effective porosity, in a certain range, the effective porosity is smaller than the total porosity, with the increase of porosity, effective porosity to total porosity, visible when the same total porosity, permeability coefficient of permeable pavement may also be different. A new pore structure model is proposed by Kuang and so on. The permeability coefficient can be fitted by the relevant parameters obtained by the experiment.

Rainwater runoff contains a large amount of nitrogen and phosphorus, which is one of the important reasons for the eutrophication of natural water bodies. Kelly found that the total nitrogen removal rate was poor in the experiment. The removal rate of nitrogen increased with the increase of sand layer at the bottom of the permeable pavement. In the experiment, Tota-Maharaj found that the removal rate of total phosphorus is very high, which can reach $78 \%$.

Microbes have a certain effect on the removal of pollutants on the permeable pavement. Newman found that a microbial community could quickly degrade pollutants in the water through the surface of the water. The microbiological characteristics of different types of permeable pavement were studied by Fan. It was found that the characteristics of microbes in different permeable pavement were different (Table 3)

Table 3. Microbial Characteristics in Different Types of Permeable Pavement.

\begin{tabular}{cc}
\hline Surface material & Characteristic \\
\hline JW permeable pavement & species and quantity of bacteria are high with high activity of microbes \\
Microporous asphalt pavement & Large number of fungi with high activity of nitrogen compounds \\
Permeable concrete brick & many actinomycetes, low activity and high metabolic diversity \\
Glass fiber permeable concrete brick & Small number of microbes and high metabolic diversity \\
\hline
\end{tabular}

Microbial activity is affected by factors such as water quality and temperature. Mbanaso [67] Found that glyphosate containing more in runoff (Glyphosate Containing, Herbicide, GCH), the microbial population will reduce the permeable pavement, when the herbicide concentration reached $72 \mathrm{mg} / \mathrm{L}$, the ability of microbial degradation of pollutants is greatly reduced, water quality variation. The appropriate temperature is beneficial to improving the ability of microorganism to degrade pollutants. It is proposed to provide more suitable temperature for microorganisms through geothermal, and to improve the ability of microorganism to remove pollutants.

The surface of the permeable pavement contains a lot of impurities. When the rain is permeable in the permeable pavement, the permeable pavement can intercept the particles of the rain water, and the rain will also carry the particles on the surface of the building material. Elizabeth found that the particle size of 5-6um particles was higher than that of raw water, indicating that pollutants released from the base material to rainwater were released during the process of rainwater infiltration.

Pervious pavement can also effectively reduce the impact of the "heat island effect" on the city. Rainwater stored in permeable base materials will be drained away by evaporation. During the evaporation process, rainwater will take away the heat stored in the ground, thus reducing the surface temperature and reducing the urban heat island effect. Takashi Asaeda found that after the rainfall, the temperature of the permeable pavement is lower than that of the traditional pavement, and the "cooling" effect will continue for a period of time. Within a certain range, the more moisture the permeable pavement contains, the lower the temperature of the permeable pavement surface. At the same time, this low temperature state will last for a longer. Can effectively reduce the temperature of the surrounding environment to permeable pavement watering in the daytime, but the water storage capacity of high latent heat of evaporation of water, if not there at night in this part of the permeable pavement, heat water storage will be distributed to around, the ambient temperature increases, so should be moderate watering, water evaporation in the daytime complete, to minimize the residual water storage effects on the surrounding

Research on permeable pavement is relatively small and unsystematic in China, and it does not study the flow rate of water through the surface and the removal of pollutants. The studies on Xie only on the base of different material interception effect; Zhao on permeable pavement runoff reduction was studied, but domestic research for permeable pavement is not system, need to control runoff and Study on permeable pavement in a combination of reduction of non-point source pollutants, and to 
analyze the influence of rainfall characteristics and the structure features and other factors effect on the use of permeable pavement.

\section{Acknowledgments}

This work was supported by a grant from Nanjing Vocational Institute of Transport Technology (JZ1711).

\section{References}

[1]. Sansalone J, Kuang X, et al. Permeable Pavement as a Hydraulic and Filtration Interface for Urban Drainage[J]. Journal of Irrigation \& Drainage Engineering, 2008. 134(5): 666-674.

[2]. Roseen R M, Ballestero T P, et al. Seasonal Performance Variations for Storm Water Management Systems in Cold Climate Conditions [J]. Journal of Environmental Engineering, 2009. 135(3): 128-137.

[3]. Bean E Z, Hunt W F, et al. Evaluation of Four Permeable Pavement Sites in Eastern North Carolina for Runoff Reduction and Water Quality Impacts [J]. Journal of Irrigation \& Drainage Engineering, 2007. 133(6): 583-592.

[4]. Boving T B, Stolt M H, et al. Potential for localized groundwater contamination in a porous pavement parking lot setting in Rhode Island [J]. Environmental Geology, 2008. 55(3): 571-582. 